\title{
Developing a Waqf Crop Micro Takaful Framework Through Crowdfunding-Waqf in Malaysia
}

\author{
Fauzilah Salleh ${ }^{1, *}$, Muhammad Shahrul Ifwat Ishak ${ }^{1}$, Normazlina Abu \\ Bakar $^{1}$, Siti Maria Wardayati ${ }^{2}$ \\ ${ }^{1}$ Faculty of Business and Management, Universiti Sultan Zainal Abidin, Terengganu, Malaysia \\ ${ }^{2}$ Faculty of Economics and Business, University of Jember, Jember, Indonesia \\ *Corresponding author. Email: fauzilah@unisza.edu.my
}

\begin{abstract}
The agriculture sector contributed 7.1 per cent (RM101.5 billion) to the Gross Domestic Product (GDP) with $10.36 \%$ for employment in 2019. Agriculture is considered a high-risk industry due to adverse weather conditions and crop diseases outside the control of farmers that causes serious consequences, such as crop failure, poverty, and food insecurity that could adversely affect the sector's economic development potential. This scenario needs to have a crop insurance scheme to protect the financial loss. However, national crop insurance schemes have not yet been implemented in Malaysia compared to neighbouring countries like Thailand, the Philippines, and Indonesia. This protection is significant for smallholder farmers to provide sustainable economic growth and food security. Questions arise, if this scheme is developed, are small farmers able to contribute to this scheme and what about its sustainability? Therefore, this study aims to develop a sustainable 'Waqf Crop Micro Takaful Framework' (WCMTF) for smallholder farmers' contribution by the takaful industry in developing Crop Micro Takaful Scheme. Next, to recommend ways and policies to enhance the optimisation of crowdfunding in developing WCMTF. In this regard, Waqf is utilised as a way of financing, while crowdfunding is its platform. The crowdfunding platform can also allocate society to agricultural development in terms of moral and financial support. In terms of government policy, this project supports the agriculture sector has enabled farmers to grow economically and bring substantial employment opportunities to the country, especially to the farmers who belong to the B40 group. This program's importance will support the bumiputra economy, which is said to not grow in line with the country's development and, in turn, increase continued prosperity through Islamic financial hub in key economic growth activities (KEGA) 1, to achieve Prosperity Together Vision 2030.
\end{abstract}

Keywords: Waqf, Crop, Crowdfunding, Micro Takaful.

\section{INTRODUCTION}

Agriculture in Malaysia focuses on transforming a traditionally small-scale, production-based sector into a large-scale agribusiness industry that contributes to economic growth and sustainability. The agriculture sector contributed 7.1 per cent (RM101.5 billion) to the Gross Domestic Product (GDP) with $10.36 \%$ for employment in 2019 (Statistics Department, 2020). Agriculture is an essential industry for almost all countries, especially for developing countries such as Malaysia, because it enables the government to generate income and sustains food supply. The major contributors are from large and small farms. However, the average size of the farm is small. For example, in rice production, 40 per cent of 0.3 million farmers are full-time farmers who own less than 1 ha of land. About four-fifths of the farms are less than 0.5 ha in the fruit sector, and only 33 per cent are considered "commercial". As for vegetable farms, about 80 per cent of them operate farms less than 2 hectares [1]. The same goes for aquaculture and livestock. 
However, agriculture is also considered a high-risk sector as the crop production risk continues due to adverse weather conditions and crop diseases that farmers cannot control. Flood, drought, anxiety, and other natural disasters can result in severe consequences, such as crop failure, poverty, and food insecurity, affecting the sector's economic development potential. Various factors affect agricultural risks in Malaysia due to climate change, uncertainty in yields and prices, inadequate markets, inadequate financial services, and insufficient risk reduction instruments [2]. These factors threaten farmers' livelihoods and income and challenge the agricultural sector's viability as they can be part of the solution to the endemic poverty of farmers and agricultural labour [3].

The national agriculture crop insurance scheme has not yet been implemented in Malaysia [4] compared to neighbouring countries like the Philippines and Indonesia. In the Philippines, The Farmer Protection governs Philippine Crop Insurance Corp. (PCIC), established on June 11, 1978. Meanwhile, in Indonesia, the agriculture insurance activities and the Empowerment Act or FPE Act (Law No. 19/2013) provide insurance protection to farmers against losses arising from natural calamities, plant diseases and pest infestations of crops

Meanwhile, in Malaysia, farmers have been forced to prepare and make decisions about environmental uncertainties. They need to practice many of life's best ways and strategies to keep their crops, dare to deal with unexpected natural hazards like floods, drought, pests, and diseases [5]. Some private commercial insurance for cocoa, fruit, coconut oil palm, and rubber for plantation export crops has been limited since the 1980s - all these crops insured under plantation or forestry fire policy and additional perils cost a high premium. The Malaysian government invited the National Insurance Association of Malaysia (NIAM) in 2002 for a national agriculture insurance program implementation. In 2004, with the Zurich branch's support, the partner reinsurance company, NIAM, ready with the designed proposal named Multiple Paddy Crop Insurance (MPCI) program. Unfortunately, although the proposal to establish the program gets well to feedback and has received NIAM's members, farmers community, and the government, the program is cancelled from being implemented due to the high premium rates. The benchmarking of some countries in our region like the Philippines and Indonesia that have initiated the implementation of micro-insurance schemes has to implement as it contributes significantly to the rural community's economic well-being, especially to smallholders. Questions arise, if this scheme is developed, are smallholder farmers able to contribute to this scheme and what about its sustainability? Therefore, this study aims to develop a sustainable 'Waqf Crop Micro Takaful Framework' (WCMTF) for smallholder farmers' contribution by the takaful industry in developing Crop Micro Takaful Scheme. Next, to recommend ways and policies to enhance the optimisation of crowdfunding in developing WCMTF.

\section{LITERATURE REVIEW}

\subsection{Takaful Contribution Issues of Crop Micro Takaful}

Takaful contract is an insurance contract base on Islamic models of financing concepts where participants pay contributions to the takaful operators [6]. The takaful operators act to manage risk and invest the contribution fund. The participants' contributions are credited into the pooling fund, which is then invested, and the profits generated will pay back to the participants. Takaful may have three pooling funds: takaful funds, investment funds, and corporate funds [7]. Issues in the payment of takaful contributions are essential to ensure the takaful policy's sustainability [8]. Referring to agriculture insurance, smallholders, on average, are among the B40s who are likely to be unable to contribute to the scheme. However, protecting these crops is vital for protecting against losses due to their crops' damage. Similarly, this scheme's continued contribution is also crucial for the sustainability of the agriculture takaful scheme. Without such donations, it may not last long as the fund for tabarru' will be reduced and eventually will not last long

\subsection{Waqf}

In the Waqf Model, the takaful operator's shareholders are the contributors to a fund that they cede to be used to compensate persons who suffer loss. The policyholder, filling out a form and a subscript to the fund. The shareholders determine to whom and how much money should be paid. They also choose investments and use of surplus. The Wakala Waqf model implies that the takaful participants contribute money to the fund, which is considered a charitable contribution and could include compensation for property loss by any member. The operator is entitled to management fees and a portion of returns on investment as mudarib [9]. In order to practice the takaful model based on the Waqf concept, it is necessary to combine the spirit of Takaful with the spirit of Waqf. It indicates that participants will have 
to waive the right of their ownership in the Takaful fund so as it can be converted into a Waqf entity in line with the Tabarru principle, which was previously stated.

Similarly, participants enjoy two types of rewards: a spiritual satisfaction as well as specific benefits provided through the Takaful contract [10]. It was discovered that just a few Malaysian operators have applied the Waqf principle when they develop their product. STMB for example, the first Malaysian Takaful operator in 2002 began to offer the Takaful product that applied the Waqf concept. It has lasted until 2009 because the low demand for this product [11]. According to findings from a previous study [12], the Waqf principle is not the sole Islamic concept utilised by STMB to that particular product. Similar to other products, Tabarru', Wakala, and Mudharabah principles have been also employed concurrently. In fact, Waqf is not a component of the Takaful fund collecting. Nonetheless, it is carried out once the certificate has matured or upon the participant's death. However, the participants' Takaful profits would be distributed to any social institutions (mosque, orphanage, old-age home, and school) throughout their lives. Thus, prior to the maturity of the certificate, a portion of the participants' contributions will be considered Waqf funds, which must be managed responsibly by the operators. Among the difficulties inherent in offering Takaful products based on the Waqf is the idea of legal restrictions. In Malaysia, the federal constitutions state that the State Islamic Religious Council (SIRC) is the absolute authority over religious matters, including the management of the Waqf fund. Additionally, each state has enacted its own statutes/rules governing the management of the Waqf fund. In this event, the SIRC will assume the existing functions of Takaful operators as Waqf fund managers, which could generate complications in the future. This strategy would also address the question of cash Waqf (while some scholars permit its practise, it should maintain and generate benefits for others). As Takaful contains investment components, the issue will arise if the investment suffers a loss). The third issue is sharing underwriting surplus when the Almighty owns the Waqf fund. Both operators and participants are ineligible to benefit from the Waqf fund's surplus. Malaysia does not yet fully implement Waqf contracts in Takaful, which violates Malaysia's current practise of sharing underwriting surplus.

Similarly, [13] it was found in his study that the Waqf concept, as practised in other countries, is used to replace the tabarru' rule, pursuant to which the participant contributes to the Waqf fund. The model's remaining operations were identical to those of other models. This was also consistent with the WakalaWaqf concept offered by [14] in Pakistan at the Second International Symposium on Takaful 2006 in Malaysia. This research would suggest the original Waqf model: a collaboration between Waqf institutions and Takaful operators. It is necessary to realise the model and fulfil the aim of the Waqf fund, which is to expand its advantages to the entire community and provide an infinite number of rewards for the Waqf provider, particularly in the hereafter. The Waqf contract would be implemented during both the fund collection and distribution processes. Through SIRC, Waqf institutions would be tasked with the responsibility of collecting Waqf funds, while Takaful operators would be tasked with supervising underwriting activities and disbursing rewards to participants.

\subsection{Crowdfunding}

The term "crowdfunding" is derived from the broader concept of "crowdsourcing", described as a creative solution for fundraising for groups and individuals. Initially, crowdfunding was used to fund artistic projects [15]. However, it has quickly spread to other industries, such as technology, start-ups based on information, and the creation of new products [16]. Small and micro-businesses, as well as individual entrepreneurs, are finding new ways to raise money in an internet-dominated world [17]. Crowdfunding, via the internet, facilitates the availability of financial resources, either in the form of donations or in exchange for a reward and/or voting rights, to support initiatives with defined goals [18].

Regarding achievement, [19] claims that the crowdfunding sector experienced significant growth, raising over $\$ 34.4$ bn in 2015 to double its 2014 figure of $\$ 16.2 \mathrm{bn}$. However, it cannot be denied that many crowdfunding projects fall short of their financing goals. [19] asserted that only about $36 \%$ of all financed projects successfully raised funds on Kickstarter in 2015 , compared to $10 \%$ on the Indiegogo platform. Thus, knowing the elements that influence customers' willingness to engage becomes critical for businesses and entrepreneurs considering using crowdfunding to support their ventures. The success rate of crowdfunding projects on most platforms is less than 50 per cent [19]. Using crowdfunding needs to involve more people, as an individual can be a potential Crowdfunder. exploring consumers' behaviour as capital providers may be crucial for the success of these projects. 
While many types of crowdfunding, such as reward, donation, equity, and lending, are offered, all of them is regularly associated with community-based experiences resulting from social interaction [20] and [21]. Crowdfunder's also derive consumption value from entrepreneurial initiatives [22;6]. These different benefits create intrinsic or extrinsic motivation for funders to participate in crowdfunding [23]. This result in so-called value-added because the crowd's wisdom can add value beyond the purely financial sphere [24].

Regarding Malaysia, where crowdfunding is still new, like other countries have taken steps to provide necessary adjustments to their regulatory regimes to accommodate crowdfunding, Malaysia is also no exception. However, the current phase of the efforts is focused mainly on financial return crowdfunding, which governs either P2P lending activities or equity crowdfunding exercises, or both. In many jurisdictions, including Malaysia, laws and regulations for community-based crowdfunding, particularly donation-based crowdfunding, remain unclear [25]. On the other side, since Malaysia is recognised as among the most progressive countries in Islamic finance development, Islamic crowdfunding should be considered a potential sector. In this regard, Shariah contracts can be applied, particularly Waqf promoting donation crowdfunding. Therefore, Waqf based crowdfunding can be an intriguing part that could be implemented as a platform for the operators as mudarib to gain the capital to protect the smallholder farmers.

\section{RELEVANCE TO GOVERNMENT POLICY}

This study meets the relevance to "Shared Prosperity Vision 2030 " (SPV2030) agenda as follows.

\subsection{Strategic Thrust 2-Key Economic Growth Activities.}

WCMTF will help achieve WKB2030 through two KEGA 1 and KEGA 12 activities by increasing Islamic finance activities and the green economy. Developing WCMTF for smallholder farmers in Malaysia would contribute to the development in Takaful as a preventive measure to face any risks that could affect future smallholder crops to ensure crop sustainability and resilience.

\subsection{Smallholders Income Stability}

Further, this program would improve the income of smallholders generally classified as B40 and improve the bumiputra economy, which is said to not grow in line with the country's development. Crop Micro Takaful will play a significant role in encouraging smallholders' farmers since it ensures stability in income as it protects the smallholders against losses caused by crop failure. It acts like a tool that allows smallholders to manage their yield and price risks.

\subsection{Sustainability Agriculture Business}

Furthermore, this research will help those who desire to start the agriculture business and do not have to worry about the problem that may occur in the future. This will provide an opportunity for small agropreneurs to contribute to the country's GDP.

\section{METHODOLOGY}

This research used both quantitative and qualitative approaches. Quantitative research is a descriptive study of farmers' risks regarding frequency and severity using the survey method through questionnaire distribution. Using simple sampling, surveys were provided to ensure high response rates to 400 smallholders (less than 2 hectares) of rice, fruits, and vegetables.

Qualitatively, however, analysed the documents to compare with the crop insurance schemes available in the Malaysian market and compare with two neighbouring countries, Indonesia and the Philippines - all types of a peril covered in the crop insurance scheme. As for the former, this study utilises books, journals, reports, thesis, and seminar papers. Therefore, it would help the researcher to obtain an overview of the concept of Waqf, which was discussed widely among scholars. Library research was also significant to understand the concept of crowdfunding.

As for the semi-structured interview, this method provides more flexibility as it allows respondents to explain more to enables the researcher to obtain adequate information from them. Through the semistructured interview, respondents can respond to questions in detail based on their preferences and experiences [26]. Thus, this method was utilised since it was a practical way to gather facts, attitudes, and opinions and help researchers raise important new issues through open-ended questions. 
To explain the objectives, in-depth interviews were conducted with insurance companies in Indonesia and the Philippines. Subsequently, focus group discussions worked with the following groups: Bank Negara, Takaful Operators, Malaysia Takaful Association, the Crowdfunding platform, Shariah scholars, Waqf Institutions and Ministry of Agriculture and Food Industry (MAFI)

After transcription, the data was analysed based on Atlas-ti software due to many participants. The content analysis method was also needed since it provides a systematic and objective means to make valid inferences from verbal, visual or written data to describe and quantify specific phenomena [27]. However, the qualitative research design is considered not ample without the triangulation concept [28]. This regard requires more than one approach in investigating one research question to yield robust findings. The practice was becoming prominent in social and behavioural research for providing more information from the proposed model. Thus, the Focus Group Discussion (FGD) was conducted to generate further the refined model and item for each potential variable underlined in this study.

\section{RESULTS}

This study adds to the body of knowledge on Waqf and crowdfunding, particularly in the context of Malaysia. The study presents a viable alternative model for Waqf institutions to develop WCMTF by leveraging crowdfunding as a funding source. The donation-based crowdfunding model and the rewardbased crowdfunding model are combined in this model. This strategy differs from the current method of raising cash Waqf, which is also carried out online by financial institutions and state government organisations. Later, the cash Waqf fund was converted into illiquid assets, such as the construction of hospitals and educational institutions, as well as the acquisition of machinery and assets. The proposed model in this study, on the other hand, is designed to assist the Waqf institution in building a WCMTF. The crowdsourcing approach is being used to gather funds in Malaysia for the construction of the WCMTF. The money raised through the crowdfunding concept is based on donations and rewards, not on the nature of cash Waqf.

\section{CONCLUSION}

From the developed WCMTF, the Waqf institution and crowdfunding can complement each other. WCMTF has the potential to have a substantial impact on Waqf institutions, society, and economy, as well as academia and theory. As this model incorporates crowdfunding for developing Waqf Crop Micro Takaful Scheme (Waqf CMTS), it benefits Waqf institutions. For example, this incorporation of crowdfunding aids in raising the profile of Waqf organisations and their projects, allowing them to progress further. Many donors or investors will be enticed to put their money into the Waqf institution's projects. As a result, the Waqf institution can fund the development of WCTM without relying heavily on government funds.

The model was designed to help society and the economy. Because this strategy emphasises the growth of Waqf CMTS, it fosters a vibrant socioeconomic environment. In the agriculture sector, the projects could result in job creation, income production, poverty reduction, and other benefits. Indeed, by providing money to the proper causes, this strategy aids society in becoming charitable. Meanwhile, crowdfunding is one of the economic system's redistribution methods; it boosts the economy by increasing wealth, consumption, and investment. It contributes to the efficient allocation of resources in the economy.

The academic and theoretical approach proposed contributes to the existing literature in Takaful, crowdfunding, and Waqf. This research adds to the existing body of knowledge about crowdfunding for Waqf CMTS and its development, notably in Malaysia. This is because Waqf had played a significant role in the socio-economic development of Muslims in history. This model is expected to positively change stakeholders' perceptions about the dynamics and potentials of this voluntary sector.

\section{ACKNOWLEDGMENTS}

This article has received financial and technical support from the Centre for Excellence in Management Research and Incubation (CREIM), University of Sultan Zainal Abidin, Malaysia.

\section{REFERENCES}

[1] T. Ling, and Shamsudin, Mad Nasir and Bing, Wang and Nhung, Pham and Rabbany, Md, 'Mitigating the impacts of COVID-19 on domestic rice supply and food security in Southeast Asia," Outlook on Agriculture. 50 . 003072702110242, 2021, doi: $10.1177 / 00307270211024275$. 
[2] N. A. B. A. Aziz, N. N. B. A. Aziz, Y. B.W., Aris, and N. A. B. A Aziz, "Factors influencing the paddy farmers' intention to participate in agriculture Takaful," Procedia Economics and Finance, vol.31,pp. 237-242, 2015.

[3] N.A.S. Burhan, R. Che Razak, F. Salleh, M.E. Labastida Tovar, "The higher intelligence of the 'creative minority' provides the infrastructure for entrepreneurial innovation," Intelligence, vol 65,pp.93-106, 2017.

[4] C. M. Reyes, A. D. Agbon, C. D. Mina, and R.A.B. Gloria, "Agricultural insurance program: Lessons from different country experiences (No. 2017-02)," PIDS Discussion Paper Series, 2017.

[5] F. Salleh, M.D. Ibrahim, A.S. Yazid, A Afthanorhan, N. Rashidand, P.L. Ghazali, "Micro small and medium enterprise demand for general takaful: proposed theoretical framework and hypotheses development", International Journal of Academic Research in Business and Social Sciences, vol. 8 no. 12, pp. 599-612, 2018.

[6] W.N.W.Daud, F.A. Zainol, F.Salleh, A.S. Yazid, S. Ismail, R. Markom, and N.D. Mukhtar, "Takaful rules and regulations for ASEAN countries: Takaful player perspectives," Proceedings of the 30th International Business Information Management Association Conference, IBIMA 2017 - Vision 2020: Sustainable Economic development, Innovation Management, and Global Growth, 2017January, pp. 2363-2369, 2017.

[7] F. Salleh, M..D. Ibrahim, R.H. Redzuan, and N. Remli., "Developing a takaful property framework for small and medium enterprises", World Applied Sciences Journal, vol. 35 no. 8, pp. 1602-1609, 2017.

[8] A. Schanz and Company, AnnualReport 2019 MNRB Holdings Berhad [internet], 2019, available from: www.mnrb.com.my/sites/default/files/annualreport-2019.pdf

[9] N.I. Abdullah, "Analysis of demand dor family Takaful and life insurance: A comparative study in Malaysia," Journal of Islamic Economics, Banking and Finance, vol. 113(470), pp. 1-20, 2012.
[10] M. I. Rosele, and A. H. Johari, "Aplikasi Takaful Model Wakaf di Malaysia: Keperluan dan Permasalahannya,"UMRAN-International of ic and Civilizational Studies, vol. 3, no.1, pp. 28-38. 2016.

[11] W. A. R. Wan Mohd Al Faizee and Y. Salmy Edawati "Takaful Wakaf diSyarikatTakaful

Malaysia Berhad: Sorotan Literatur," ISLAMIYYAT, vol. 36(2), pp. 47-56, 2014.

[12] Ashraf Md Hashim, "The collection of Waqf through insurance companies: a critical analysis of the Malaysian experience," Review of Islamic Economic, vol. 1(11), pp. 64-72, 2007.

[13] H. A. Alnemer, "Revisiting Takaful Insurance: A Survey on Functions and Dominant Models," Afro Eurasian Studies, vol. 2 (1-2), pp. 231253, 2013, available from https://dergipark.org.tr/en/pub/afes/issue/4478 3/557 006

[14] A. R. Abdul Wahab, M. K. Lewis, and M. Kabir Hassan, "Islamic Takaful: Business Models, Shari'a Concerns and Proposed Solutions,' Thunderbird International Business Review,vol. 49 (3), pp. 371-39, 2007.

[15] A. Agrawal, C. Catalini, and A. Goldfarb, "The Geography of Crowdfunding," NBER Working Paper no. 16820, 2011, available from: http: // www .nber .org/ papers/w16820

[16] J. Hemer, “A snapshot on crowdfunding," Working paper, Firms and Regions no. 2, Frauhofer ISI, 2011, available from: http://www.isi.fraunhofer.de/isiwAssets/docs/p/de/arbpap_unternehmen_region/ ap_r2_2011.pdf.

[17] A. Zhao, I.M.Y. Szeto, Y. Wang, C. Li, M. Pan, T. Li, P. Wang, and Y. Zhang, Y, "Knowledge, attitude, and practice (KAP) of dairy products in chinese urban population and the effects on da iry intake quality," Nutrients, vol. 9(668), pp. 110,2017

[18] T. Lambert, and A. Schwienbacher, "An empirical analysis of crowdfunding", SSRN No: 1578175,2010 .

[19] Massolution, "2015CF-crowdfunding industry report”. Ngah, K. (1987), "Kajian potensi perancangan pembangunan tanah wakaf di Pulau Pinang", Pusat Penyelidikan Dasar, Universiti Sains Malaysia. Ngah, N. (2012), 
2015, available from: www.jawhar.gov.my/index.php/ms/akhbar/123 - artikel-bh25102012

[20] A. Agrawal, C. Catalini, and A. Goldfarb, "Some Simple Economics of Crowdfunding," J. Lerner, and S. Stern, eds., Innovation Policy and the Economy, vol. 14, pp. 63- 97, 2014, Chicago, IL, USA: University of Chicago Press.

[21] Paul Belleflamme, Thomas Lambert, and Armin Schwienbacher, "Crowdfunding: Tapping the right crowd," Journal of Business Venturing, vol. 29, pp. 585-609, 2014.

[22] A. Schwienbacher and B. Larralde, "Crowdfunding of small entrepreneurial ventures" D.J. Cumming, ed. The Oxford Handbook of EntrepreneurialFinance.Oxford: OxfordUniversity Press, 2010

[23] F. Kleemann F, G.G.Voß, and K. Rieder 'Un(der)paid innovators: The commercial utilisation of consumer work through crowdsourcing," SciTechno Innovate Stud, vol. 4(1), pp. 5-26, 2008.

[24] S. A. Macht, and J. Weatherston. "The Benefits of Online Crowdfunding for Fund-Seeking Business Ventures," Strategic Change, vol.23 (1-2), pp. 1-14, 2014.

[25] A. Abdullah, "Crowdfunding as an Emerging Fundraising Tool: With Special Reference to the Malaysian Regulatory Framework". ICR Journal, vol. 7 (1), pp. 98-119, 2016, doi: https://doi.org/10.52282/icr.v7i1.286.

[26] T. May, Social Research: Issues, Methodsand Process 2nd edn. Buckingham:Open University Press, 1997.

[27] M. Bengtsson, "How to plan and perform a qualitative study using content analysis," Nursing Plus Open, vol. 2, pp. 8-14, 2016, doi: https://doi.org/10.1016/j.npls.2016.01.001

[28] A. Bryman, Social Research Methods (2nd edition). Oxford: Oxford UniversityPress, 2004. 